\title{
SEISMIC ANALYSIS OF VERTICAL IRREGULAR MULTISTORIED BUILDING
}

\author{
Nonika. $\mathbf{N}^{1}$, Gargi Danda De ${ }^{2}$ \\ ${ }^{1} P G$ student, Department of Civil Engineering, Bhilai Institute of Technology, Durg, Chhattisgarh, India \\ ${ }^{2}$ Assistant Professor, Department of Civil Engineering, Bhilai Institute of Technology, Durg, Chhattisgarh, India
}

\begin{abstract}
It is understood that buildings which are regular in elevation (regular building) perform much better than those which have irregularity in elevation (irregular building) under seismic loading. Irregularities are not avoidable in construction of buildings. However a detailed study to understand structural behaviour of the buildings with irregularities under seismic loading is essential for appropriate design and their better performance.
\end{abstract}

The main objective of this study is to understand the effect of elevation irregularity and behaviour of 3-D R.C. Building which is subjected to earthquake load.

In the present study, a 5 bays X 5 bays, 16 storied structure with provision of lift core walls and each storey height $3.2 \mathrm{~m}$, having irregularity in elevation, is considered as the soft storey 3-D structure. An Irregular building is assumed to be located in all zones. Linear dynamic analysis using Response Spectrum method of the irregular building is carried out using the standard and convenient FE software package. To quantify the effect of different degrees of irregularities all the structures are analysed. In addition, the analysis carried out also enables to understand the behaviour that takes place in irregular buildings in comparison to that in regular buildings. For this the behaviour parameters considered are 1) Maximum displacement 2) Base shear, 3) Time period.

Key Words: asymmetric building, soft story, base shear, displacement, soft storey, time period.

\section{INTRODUCTION}

Earthquake Ground Motions (EQGMs) are the most dangerous natural hazards where both economic and life losses occur. Most of the losses are due to building collapses or damages. Earthquake can cause damage not only on account of vibrations which results from them but also due to other chain effects like landslides, floods, fires etc. Therefore, it is very important to design the structures to resist, moderate to severe EQGMs depending on its site location and importance of the structure. If the existing building is not designed for earthquake then its retrofitting becomes important.

Seismic requirements were not included in building codes as early as those for wind, although some experimentation had taken place in Europe and even more in Japan, which suffered from frequent seismic activity. Some of the early approaches yielded little result, but that did not stop curious minds from experimenting. The first application of Newton's first law to building codes dealing with seismic design was reportedly made in Italy following the 1911 Messina earthquake.

The Present work is giving importance on the study of Seismic demands of some vertical irregular buildings using analytical techniques for the different earthquake zones (medium soil) of India. This involves vertical irregularities like stiffness irregularity.

\section{METHODOLOGY}

Structure has been defined into stiffness irregularity as specified in IS1893-2002 code. In this dissertation work, an effort is made to study the seismic effects on structures due to this irregularity. Different configurations of structures are considered for the FE analysis using ETABS software. FE analyses involving Modal, Equivalent Static, and Response Spectrum are studied for the structure and results like natural frequencies, mode shapes, accelerations, displacements and storey drifts are obtained for an irregular building.

\subsection{Methods of Analysis:}

I. Equivalent Static Analysis

II. Response Spectrum Analysis

\subsubsection{Equivalent Static Analysis}

The response of a structure to earthquake-induced forces is a dynamic phenomenon. A realistic assessment of design forces can be obtained only by the dynamic analysis of the building models. Although this has been recognized, dynamic analysis is used only in frequently in routine design, because such type of analysis is both complicated and time-consuming. To calculate equivalent linear static the IS 1893 (Part I): 2002 has given a formula as below.

(i) Determination of base shear $\left(\mathrm{V}_{\mathrm{B}}\right)$ of the building 


$$
\mathrm{V}_{\mathrm{B}}=\mathrm{A}_{\mathrm{h}} \times \mathrm{W}
$$

Where,

$\mathrm{Ah}=\frac{\mathrm{Z}}{2} \frac{\mathrm{I}}{\mathrm{R}} \frac{\mathrm{Sa}}{\mathrm{g}}$ Is the design horizontal seismic coefficient, which depends on the seismic zone factor importance factor, response reduction factor and average response acceleration coefficients $(\mathrm{Sa} / \mathrm{g}) . \mathrm{Sa} / \mathrm{g}$ in turn depends on the nature of foundation soil (rock, medium or soft soil sites), natural period and the damping of the structure.

\subsubsection{Response Spectrum Analysis Modeling}

This method permits the multiple modes of response to be taken into account. The response spectrum shall be performed by using design spectrum. This type is required in all building code books except for excess simple or complex buildings. The result obtained from response spectrum method in a ground motion is different from the result occurred from a linear dynamic analysis.

\section{MODELLING}

\subsection{Modeling Details of 3D Models}

Details of Buildings considered in this work are as follows:

Type of structure: Residential Building

Number of stories: 16

Height of typical floor: $3.2 \mathrm{~m}$

Column size: $300 \mathrm{mmX500} \mathrm{mm}$

Beam size: $300 \mathrm{mmX} 500 \mathrm{~mm}$

Slab thickness: $150 \mathrm{~mm}$

Masonry wall thickness: $230 \mathrm{~mm}$

Live load: $2 \mathrm{KN} / \mathrm{m}^{2}$

Floor finish: $1 \mathrm{KN} / \mathrm{m}^{2}$

Soil types considered as type II - Medium soil.

All columns are assumed to be fixed at their base.

Characteristic compressive strength of concrete, $f_{c k}: 20$ $\mathrm{N} / \mathrm{mm}^{2}$

Grade of steel: $500 \mathrm{~N} / \mathrm{mm}^{2}$

Density of Concrete: $25 \mathrm{~N} / \mathrm{mm}^{2}$

Modulus elasticity of concrete: $2000 \mathrm{~N} / \mathrm{mm}^{2}$

Poison's ratio of concrete, $\mu: 0.3$

Density of brick masonry, $\rho: 19.2 \mathrm{KN} / \mathrm{m}^{3}$

Modulus of elasticity of brick masonry: 14000 N/mm²

Poison's ratio of brick masonry: 0.2

Damping ratio: $5 \%$

\subsubsection{Seismic Calculations:}

Table 1: Seismic Calculations for All Zones

\begin{tabular}{|c|c|c|c|c|}
\hline Characteristics & Zone 2 & Zone 3 & Zone 4 & Zone 5 \\
\hline No. of stories & 16 & 16 & 16 & 16 \\
\hline $\begin{array}{c}\text { Typical storey } \\
\text { height, m }\end{array}$ & 3.2 & 3.2 & 3.2 & 3.2 \\
\hline $\begin{array}{c}\text { Seismic zone, Z } \\
\text { Response reduction } \\
\text { factor, R }\end{array}$ & 3 & 3 & 3 & 3 \\
\hline $\begin{array}{c}\text { Importance factor, I } \\
\text { Soil type }\end{array}$ & II & II & II & II \\
\hline
\end{tabular}

Seismic zone, Z (IS 1893 - 2002, clause 6.4.2, table 2)

Response reduction factor, R (IS-1893-2002, clause 6.4.2,

Table 7)

Importance factor, I (IS 1893 - 2002, clause 6.4.2, table 6)

Soil type (IS 1893 - 2002, clause 6.4.5, pg 16)

Calculation of Time period [without infill]: (IS-1893-2002, clause 7.6.1, pg 24)

$\mathrm{T}=0.075 \mathrm{~h}^{0.75}$

\subsubsection{Irregular Model (Stiffness or soft storey)}

In this irregularity, the changes made with respect to regular building are, the base story is made as soft story by increasing the height of it from the following equation,

$0.7 \times 12 \mathrm{EI} / \mathrm{L}^{3}=12 \mathrm{EI} / \mathrm{L}_{1}^{3}$

$\mathrm{L}_{1}^{3}=\mathrm{L}^{3} / 0.7 \quad$ Where, $\mathrm{L}_{1=} \mathrm{Ht}$. Of soft storey

$\mathrm{L}_{1}=1.126 \mathrm{~L} \quad \mathrm{~L}=\mathrm{Ht}$. Of regular storey

$\mathrm{L}_{1}=3.6 \mathrm{~m}$

\section{D VIEW}

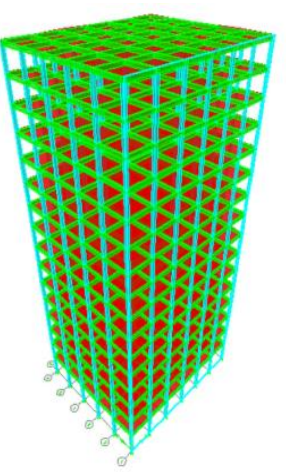

ELEVATION

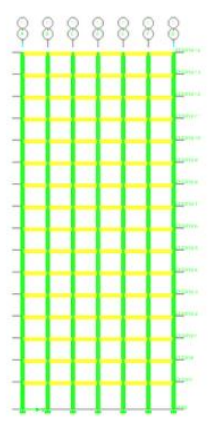

Fig 1: ETABS Model Screen shot of an irregular 16 Storied Building 


\section{RESULTS AND DISCUSSIONS}

The results of building model are presented in this chapter. The analysis carried out is equivalent static analysis and Dynamic analysis.

The result of Base shear, Lateral displacement, story drift, Fundamental time period at the first, second and third mode were presented for different irregularities for different seismic zones of India.

\subsection{ANALYSIS RESULTS OF 3D MODELS}

Model description as given below,

Soft story at Base storey as shown in Fig 1

\subsubsection{Base Shear of Irregular Model (SOFT STOREY) For Different Zones}

Table 2: Base shear of model for different zones

\begin{tabular}{|c|c|}
\hline ZONES & BASE SHEAR IN KN \\
\hline 2 & 437.09 \\
\hline 3 & 699.32 \\
\hline 4 & 1048.98 \\
\hline 5 & 1573.51 \\
\hline
\end{tabular}

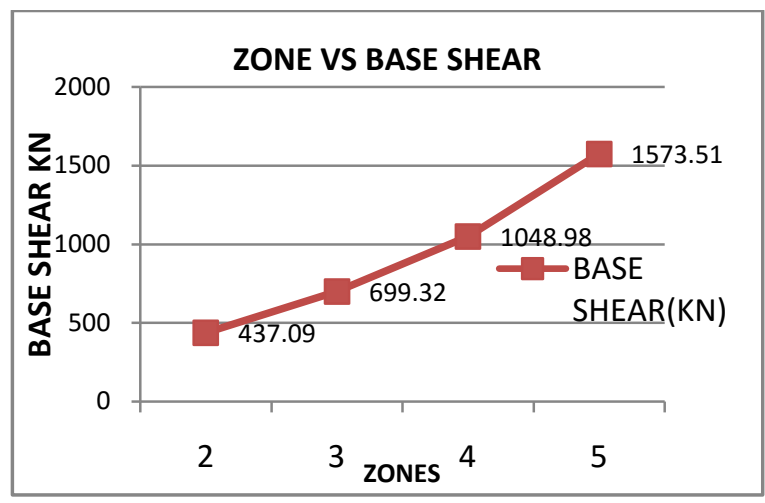

Chart 1: Graph of Zone v/s Base shear for irregular model

Chart 1 shows the graph of Zone v/s Base shear of an Irregular model i.e. Stiffness irregularity (Soft storey). It shows that as the zone increases Base shear also increases, so the maximum Base shear is $1573.51 \mathrm{KN}$ in zone 5 which is the most vulnerable seismic zone of India.

\subsubsection{Results of Top Storey Displacement of} Irregular Model (SOFT STOREY) for Different

\section{Zones}

Table 3: Displacement of model for different zones

\begin{tabular}{|c|c|}
\hline ZONES & DISPLACEMENT IN MM \\
\hline 2 & 23 \\
\hline 3 & 36.8 \\
\hline 4 & 55.1 \\
\hline 5 & 82.7 \\
\hline
\end{tabular}

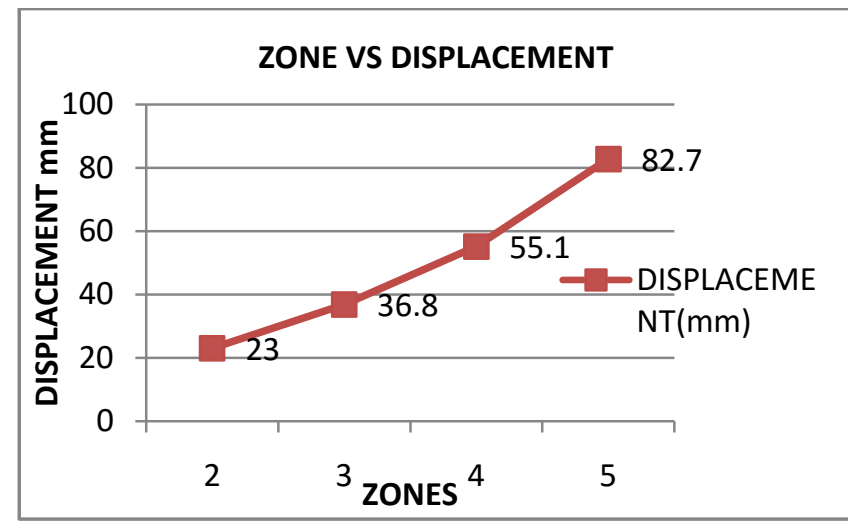

Chart 2: Graph of Zone v/s Displacement for irregular model

Chart 2 shows the graph of Zone v/s Displacement of an Irregular model i.e. Stiffness irregularity (soft storey). It shows that as the zone increases Displacement also increases, so the maximum Displacement is $82.7 \mathrm{~mm}$ in zone 5 which is the most vulnerable seismic zone of India.

\subsubsection{Storey Drift at Each Floor for irregular Model (SOFT STOREY)}

Table 4: Storey drift of model 3 for all storeys

\begin{tabular}{|c|c|c|c|c|}
\hline STOREY & \multicolumn{4}{|c|}{ STOREY DRIFT } \\
\hline & Zone 2 & Zone 3 & Zone 4 & Zone 5 \\
\hline 0 & 0 & 0 & 0 & 0 \\
\hline 1 & 0.000144 & 0.000211 & 0.000301 & 0.000435 \\
\hline 2 & 0.000175 & 0.000275 & 0.00041 & 0.000611 \\
\hline 3 & 0.00022 & 0.000352 & 0.000527 & 0.00079 \\
\hline 4 & 0.000261 & 0.000417 & 0.000626 & 0.000938 \\
\hline 5 & 0.000293 & 0.000469 & 0.000703 & 0.001055 \\
\hline 6 & 0.000319 & 0.00051 & 0.000765 & 0.001147 \\
\hline 7 & 0.000341 & 0.000545 & 0.000817 & 0.001226 \\
\hline 8 & 0.00036 & 0.000576 & 0.000864 & 0.001297 \\
\hline 9 & 0.000378 & 0.000605 & 0.000907 & 0.00136 \\
\hline 10 & 0.000393 & 0.000629 & 0.000944 & 0.001416 \\
\hline 11 & 0.000407 & 0.000652 & 0.000978 & 0.001466 \\
\hline 12 & 0.000421 & 0.000674 & 0.001011 & 0.001516 \\
\hline 13 & 0.000436 & 0.000697 & 0.001045 & 0.001568 \\
\hline 14 & 0.00045 & 0.00072 & 0.00108 & 0.00162 \\
\hline 15 & 0.000472 & 0.000752 & 0.001125 & 0.001686 \\
\hline 16 & 0.000449 & 0.000715 & 0.001071 & 0.001604 \\
\hline
\end{tabular}

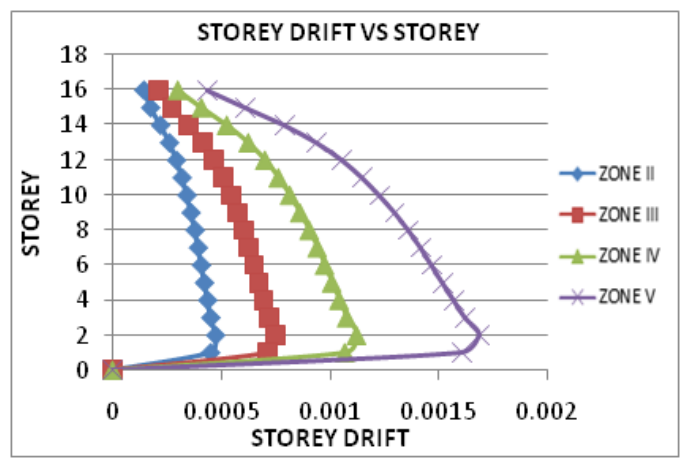

Chart 3: Graph of Storey drifts v/s Storey for irregular model 
Chart 3 shows the graph of Storey drifts v/s Storey of an Irregular model i.e. stiffness irregularity (soft storey) in all seismic zones. It shows that from base storey to $14^{\text {th }}$ storey the storey drift gradually increases but in $15^{\text {th }}$ and $16^{\text {th }}$ storey it decreases because usually storey drift is maximum in middle portion of the structure.

\subsubsection{Mode Shapes of Irregular Model (SOFT STOREY)}

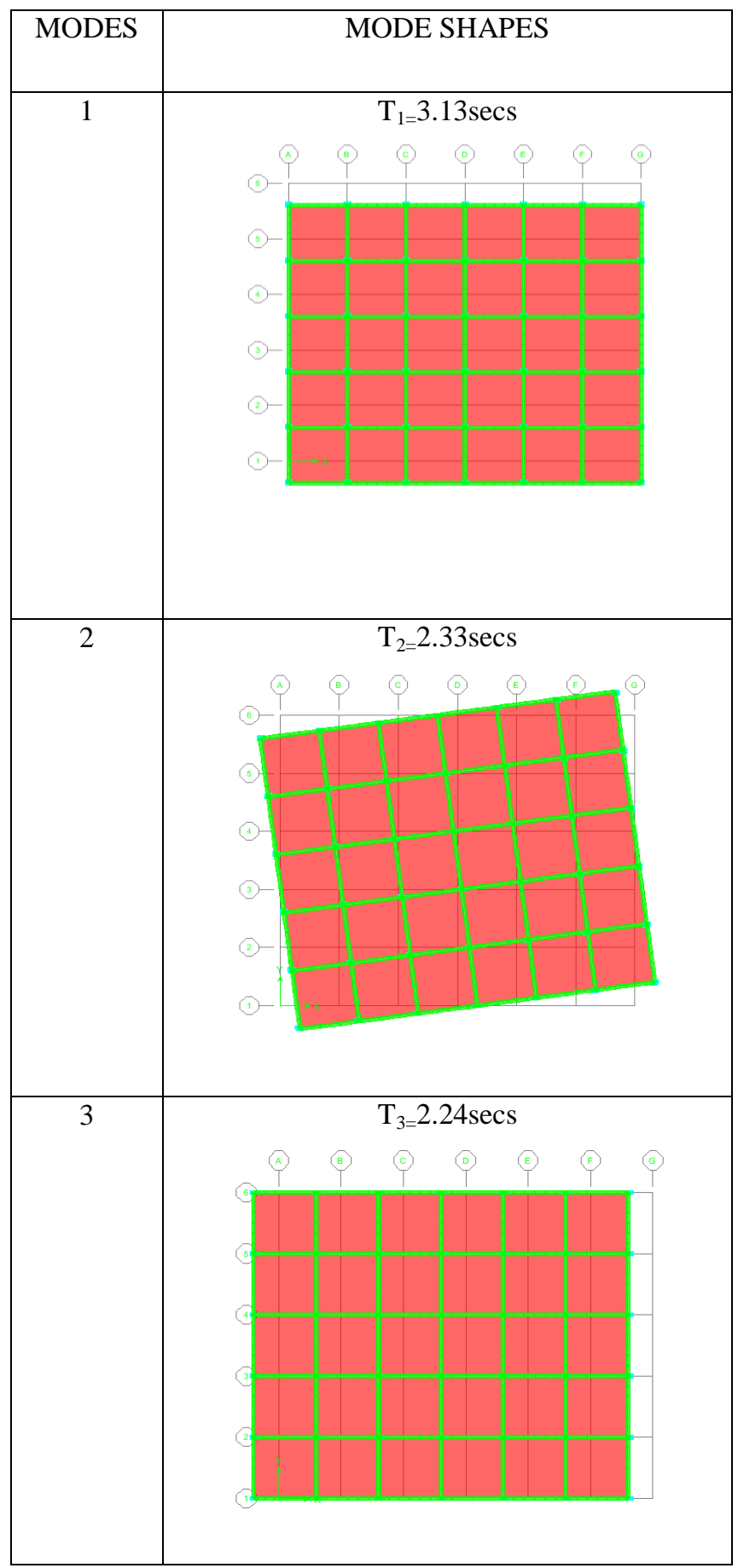

Fig 2: Mode shapes of Irregular model
In an Irregular model,

(a) First mode shape is Translation along Y -direction

(b) Second mode shape is Torsional mode and

(c) Third mode shape is Translation along X -direction.

4.1.5 Time Period at different mode of irregular model (SOFT STOREY)

Table 5: Time period in different modes

\begin{tabular}{|c|c|}
\hline MODES & TIME PERIOD(SECS) \\
\hline 1 & 3.13 \\
\hline 2 & 2.33 \\
\hline 3 & 2.24 \\
\hline 4 & 1.04 \\
\hline 5 & 0.77 \\
\hline 6 & 0.74 \\
\hline
\end{tabular}

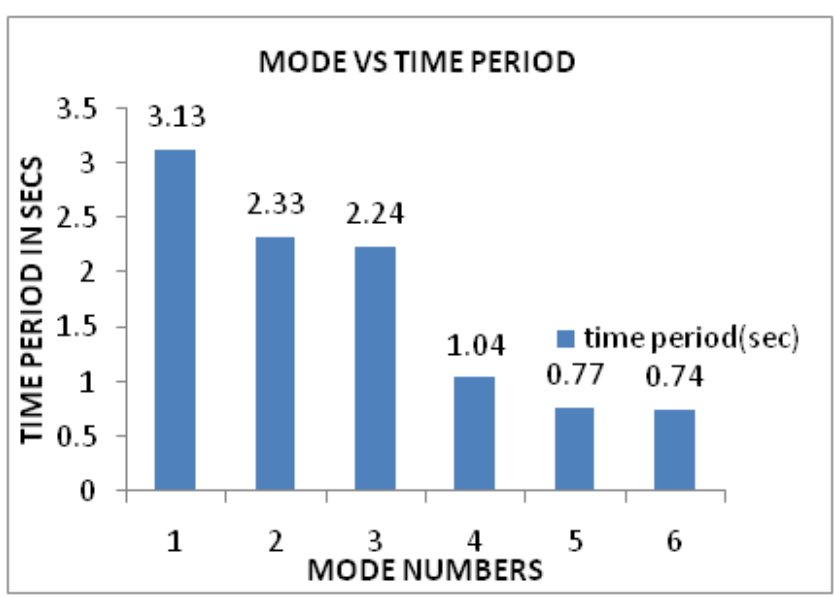

Chart 4: Graph of Mode v/s Time Period for irregular model

Chart 4 shows the graph of Mode v/s Time period of an Irregular model i.e. stiffness irregularity (soft storey). It shows that as the mode number increases the Time period decreases, so the maximum Time period is $3.13 \mathrm{secs}$ in mode 1.

\section{CONCLUSION}

When irregular buildings are analyzed using linear equivalent static analysis and Response spectrum analysis considering different seismic zones according to code provisions, the results obtained highlights the importance of mass, stiffness and geometry of the structure. Following broad conclusions can be made in this respect:

$>$ This study quantifies the effect of vertical irregularities in mass and stiffness on seismic demands.

$>$ From the overall study and observation it can be conclude that, Base shear and lateral displacement 
will increases as the seismic intensity increases from zone-2 to zone-5 which indicates more seismic demand the structure should meet.

$>$ The drift is observed in the storey in which the stiffness is reduced.

$>$ As stiffness increases frequency of the structure increases.

$>$ Stiffness is dependent on mass of the structure.

\section{REFERENCES}

[1] Ravi Kumar C M and Babu Narayan K S. et al.,"Effect of Irregular Configurations on Seismic Vulnerability of RC Buildings", National Institute of Technology, Surathkal, Architecture Research 2012, 2(3): 20-26.

[2] Devesh P. Soni and Bharath B. Mistry."Qualitative review of seismic response of Vertically Irregular Building Frames", ISET Journal of Earthquake Technology, Vol 43, No.4, December 2006, PP 121 - 132.

[3] Bhattacharya S.P and Chakra borty S, et al., "Estimation of storey shear of a building with Mass and Stiffness variation due to Seismic excitation", International journal of civil and structural engineering, volume 1, no 3, 2010, Assistant Professor, Department of Architecture, Birla Institute of Technology, Mesra.

[4] George k. Georgoussis. "Simplified dynamic analysis of eccentric buildings with a setback the effect of stiffness irregularity".Department of civil and construction engineering, school of pedagogical and technological education (aspete), Attica, Greece.

[5] Misam Abidi, Mangulkar Madhuri. N. "Review on Shear Wall for Soft Story High-Rise Buildings", International Journal of Engineering and Advanced Technology (IJEAT), ISSN: 2249 - 8958, Volume-1, Issue-6, August 2012

[6] Al-Ali and Krawinkler. 1998, "Effect of vertical irregularity on seismic behavior of building structures", Department of civil \& environmental engineering, Stanford university.

[7] Vinod Kota Sadashiva., (2010), "Quantifying structural irregularity effects for simple seismic design", the department of civil and natural resources engineering, University of Canterbury Christchurch, New Zealand.

[8] IS: 1893 (Part 2): 2002 Criteria for Earthquake Resistant design of structures.

[9] Pankaj Agarwal and Manish Shirkhande(2010), "Earthquake Resistant Design of Structures" Prentice Hall of India Private Limited, New Delhi, India.

[10] Dr. S.K. Dubey, P.D. Sangamnerkar. "Seismic behaviour of asymmetric RC buildings", International Journal of Advanced Engineering Technology E-ISSN 0976-3945, Professor \& Head Dept of Civil Engineering, MANIT, Bhopal.

[11] Thuat V. Dinh and Toshikatsu Ichinose." Criterion for Preventing Formation of Story Mechanism in Vertically Irregular Wall Buildings", Journal of Advanced Concrete Technology Vol. 2, No. 3, 1-10, October 2004.

[12] Poonam, Anil kumar and Ashok k.Gupta "Study of response of structurally irregular building frames to seismic excitations".

\section{BIOGRAPHIES}
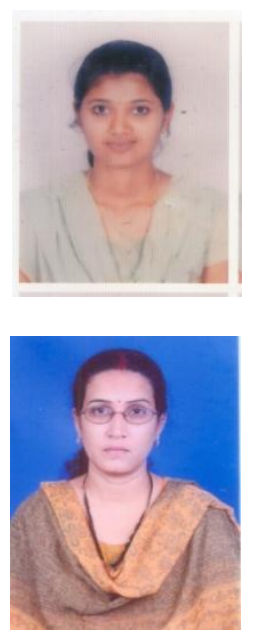

Nonika. $\mathbf{N}$ is a PG student, doing her M.Tech in Structural Engineering at Bhilai Institute of Technology, Durg under Chhattisgarh swami Vivekananda technical university

Gargi Danda De, Assistant Professor of Bhilai Institute of Technology, Durg, CG. has 11 years field and teaching experience. She has several papers in reputed national and international journals and conferences. She is a member of Indian Institute of Engineers (India). 